\title{
MOLECULAR CHARACTERIZATION OF SECONDARY METABOLITE PRODUCING STREPTOMYCES SPECIES
}

\author{
*Jodhawat Nandini, Gehlot Praveen' Songara Dimple and Kaur Swarnjeet \\ Microbiology and Mycology laboratory' Department of Botany, JNV University, Jodhpur-342001, Rajasthan, India \\ *Corresponding author's Email-njodhawatvyas@gmail.com, Telephone number: 0291-2639640, Mobile +919829178301
}

Received 29 July 2012; Review Completed 13 Aug 2012; Accepted 26 Aug 2012, Available online 15 Sep 2012

\begin{abstract}
Actinomycetes are most prolific source of antibiotics. Present study was carried out to isolate Actinomycetes of antagonistic nature. In the present study soil samples were collected from different areas of Western Rajasthan. 10 isolates of Actinomyce tes were isolated on Actinomycetes Isolation Agar (AIA). Several biochemical and physiological tests were performed for identification of these isolates. These Streptomyces isolates were screened for antagonistic potentiality against gram-positive and gram negative clinical isolates of human pathogenic bacteria. Isolates were cultivated in fermentation media for 7 days to extract out secondary metabolites or antibiotics of antimicrobial nature. Solvent extraction method was used to purifying antimicrobial compounds from filtrate. Staphylococcus aureus, Bacillus subtilis, Klebsiella pneumonia, Salmonella typhi and Pseudomonas aeruginosa were used as test pathogen. Only isolate no. 3 and 4 was found to be effective against most of the pathogens. Maximum activity of isolate no. 3 was recorded against Klebsiella pneumonia, minimum activity against Salmonella typhi and no activity was recorded against Pseudomonas aeruginosa. Whereas isolate no. 4 showed maximum activity against Staphylococcus aureus and minimum against Salmonella typhi and chloramphenicol was used as positive control. 16S rRNA sequencing of isolate no. 3 and 4 had been done and isolate no. 3 shows $99 \%$ similarity with Streptomyces thermoliliacinus and isolate no. 4 shows $100 \%$ similarity with Streptomyces werrensis. Sequences obtained from 16S rRNA sequencing were submitted in NCBI data base. From all the results we concluded that Streptomyces isolates showed significant antagonism against test pathogens and reported first time from Western Rajasthan.

Key words: Streptomyces, antagonism, fermentation process.
\end{abstract}

\section{INTRODUCTION}

Actinomycetes are widely distributed in nature. They are found in virtually every natural substrate and are the most prolific producer of $80 \%$ of known antibiotics ${ }^{1}$. Actinomycetes are prokaryotes with extremely various metabolic possibilities ${ }^{2}$. The $\mathrm{G}+\mathrm{C}$ content of DNA of Actinomycetes ranges from 57-75 \%. The genus Streptomyces represented in nature by the largest numbers of species and varieties among the family Actinomycetaceae. They differ greatly in their morphology, physiology and biochemical activities, producing the majority of known antibiotics. The genus Streptomyces includes aerobic, Gram-positive, filamentous bacteria which produce well developed vegetative hyphae (between $0.5-2.0 \mu \mathrm{m}$ in diameter) with branches. They form a complex substrate mycelium that aids in scavenging organic compounds from their substrates. Although the mycelium and the aerial hyphae that arise from them are non-motile, motility is achieved by dispersion of spores. Spore surfaces may be hairy, smooth, spiny or warty. Streptomyces are noted for their distinct "earthy" odor that results from production of a volatile metabolite, geosmin.

Due to large geographical variations in soil type and their content in Rajasthan, it is quite likely that distribution of antibiotic or secondary metabolites producing Streptomyces is also variable. Hence, In order to overcome the disadvantages with the existing drugs and to fight the drug resistant pathogens, there is an urgent need for newer, safer and less expensive drugs from natural sources. In this view, the present study was designed with the aim of isolating and identifying Streptomyces species of Western

Rajasthan with potential antagonistic activity to overcome problem of drug resistance pathogenic microorganisms.

\section{MATERIAL AND METHOD}

\section{Sampling and Isolation}

Soil samples were collected from various habitats and $1 \mathrm{~g}$ of soil was treated with $0.2 \mathrm{~g} \mathrm{Caco}_{3}$ then dried for $1 \mathrm{hr}$ at $100^{\circ} \mathrm{C}$ in oven. 20 Actinomycetes isolates were isolated by serial dilution plating on Actinomycetes Isolation $\mathrm{Agar}^{3}$ and Starch Casein Agar ${ }^{4}$ then incubated at $32^{\circ} \mathrm{C}$ for 7 days. The colonies were purified by subculturing and pure culture was preserved on Actinomycetes Isolation Agar slants at $4^{\circ} \mathrm{C}$.

\section{Optimization of media and cultural conditions:}

The isolates were inoculated on different media i.e. Starch casein agar (SCA), Actinomycetes Isolation Agar (AIA), Nutrient agar (NA), Blood agar (BA) and International Streptomyces project (ISP) ${ }^{5}$ media, to determine and identify the suitable media, optimal nutritional and cultural conditions for growth. The effects of different incubation temperatures $\left(20^{\circ}, 30^{\circ}, 32^{\circ}, 38,40\right.$ and $\left.45^{\circ}\right)$ and $\mathrm{NaCl}$ concentrations $(1,2,5,7 \text { and } 9 \%)^{6}$ for the growth of isolates were also studied.

\section{Identification and Characterization of Isolates}

Isolates were Characterized and Identified on morphological, cultural, physiological, biochemical criteria and only the isolate which showed antagonism, identified upto molecular level.

\section{Morphology:}

CODEN (USA): JDDTAO 
The Morphology of actinomycetes isolates were examined by using cover slip culture technique ${ }^{7}$ After the growth of isolate cover slip was taken, left in air to dry, stained with Gram's stain and examined under microscope and structure was compared with Bergey's manual ${ }^{8 .}$

\section{Cultural Characters:}

Cultural characteristics of actinomycetes isolates were examined by using different media like Actinomycetes Isolation Agar, Starch Casein Agar, Nutrient Agar, Blood agar and ISP media ${ }^{5}$. Color of aerial mycelium on ISP media was observed by using color scale ${ }^{9}$.

\section{Physiological tests:}

The Physiological tests used to characterize the isolates were melenoid pigmentation, degradation of tyrosine, xanthine, urea, and citrate ${ }^{10}$. The hydrolysis of soluble starch and casein ${ }^{11}$ was detected by the presences of clear zone around the colonies.

\section{Biochemical tests:}

The biochemical tests like Gram's staining, indole formation, MR-VP, Catalase enzyme and Oxidase test etc. were performed. These tests were recorded as negative or positive ${ }^{8}$.

\section{Bacterial Culture}

The antagonistic potentiality was tested against six clinical isolates of human pathogenic bacteria. It includes two Gram positive Staphylococcus aureus and Bacillus subtilis and four Gram negative bacteria viz. Klebsiella pneumoniae, Pseudomonas aeruginosa and Salmonella typhi. These isolates were taken from the Ramdeo laboratory, of Jodhpur, Rajasthan and were identified microscopically and biochemically ${ }^{8}$

\section{Inocula Preparation}

Bacterial strains were inoculated into $10 \mathrm{ml}$ of sterile nutrient broth, and incubated at $37{ }^{\circ} \mathrm{C}$ for $24 \mathrm{~h}$. The concentration of inocula was set to 0.5 McFarland's standards ${ }^{12}$.

\section{Screening of antimicrobial activity}

Primary screening of isolates have been done by crossstreak method ${ }^{4}$ and secondary screening by solvent extraction method ${ }^{13}$. Antimicrobial activity was performed by using well diffusion assay ${ }^{14}$ against gram positive and negative bacterial strains. Each test was performed three times and activity was expressed as the mean diameter $(\mathrm{mm})$ of clear zone produced by antibacterial compounds. Chloramphenicol was used as positive control for antimicrobial activity.

\section{Primary screening}

For primary screening, Actinomycetes isolates were streaked in the middle of the nutrient agar plate as straight line and allowed to grow for 48 hours at $32^{\circ} \mathrm{C}$ and then test pathogens were streaked perpendicular to the Actinomycetes and further incubated for $24 \mathrm{~h}$. at $37^{\circ} \mathrm{C}$.

\section{Secondary screening:}

Secondary screening has been done by fermentation of Actinomycetes isolates and filtration was done by solvent extraction method.
Fermentation process ${ }^{13}$

The Actinomycetes were cultured at $30^{\circ} \mathrm{C}$ for $120 \mathrm{~h}$ in a jar fermentor.1 L medium containing of maltose $4 \%$, sodium glutamate $1.2 \%, \quad \mathrm{~K}_{2} \mathrm{HPO}_{4} 0.01 \%, \quad \mathrm{MgSO}_{4} 0.05 \%$, $\mathrm{CaCl}_{2} 0.01 \%$ and $\mathrm{FeSO}_{4} 0.005 \%$ with or without sodium alginate beads.

\section{Extraction of secondary metabolites ${ }^{13}$}

Antibacterial compound was purified from the filtrate by solvent extraction method. Ethyl acetate was added to the filtrate in ratio of 1:1 (v/v) and shaken vigorously for $1 \mathrm{~h}$ complete extraction. The ethyl acetate phase contains antibiotic substances separated from the aqueous phase. It was evaporated to dryness in water bath. The obtained compound thus used to determine the antagonistic activity.

\section{Molecular characterization of isolate:}

16s rRNA sequencing was done by isolating and purifying the genomic DNA of isolate with the help of Macrogen Genomics Korea. The 16S rRNA fragment was amplified using universal primers (forward) i.e. 518F (SEQ: CCAGCAGCCGCGGTAATACG) and 800R (TACCAGGGTATCTAATCC). The obtained sequence was analyzed for homology using BLAST N.

\section{RESULTS AND DISCUSSION}

The isolated strains were filamentous, Gram positive, non motile and aerobic in nature, having Catalase and Oxidase activities hence belonged to genus Streptomyces. Out of 10 isolates subjected for primary screening process, only isolate no.3 and 4 showed activities against tested organisms. The molecular identification of potent antibiotic producing isolate no. 3 reveals that it showed 99\% similarity with Streptomyces thermolilacinus and isolates no. 4 showed $100 \%$ similarity with Streptomyces werreansis. The results of Cultural characteristics of isolate no. 3 and 4 are presented in table 1; biochemical and physiological characteristics are presented in table 2 and antagonistic potentiality presented in table 3 .

Table 1: The cultural characteristics of Streptomyces different media:

\begin{tabular}{|ccc|}
\hline \multirow{2}{*}{ Medium } & \multicolumn{2}{c|}{ Colony color } \\
\hline AIA & Isolate 3 & Isolate 4 \\
\hline SCA & White & White \\
\hline BA & Cream white & Off white \\
\hline ISP I & White & White \\
\hline ISP II & Pinkish & White \\
\hline ISP IV & Colorless & Wight grey \\
\hline ISP V & Light pink & Grey \\
\hline ISP VI & Grey & yellowish \\
\hline
\end{tabular}

The potent isolates were selected for fermentation on the basis of its broad spectrum antagonistic activity and largest zone of inhibition. Maximum activity of isolate no. 3 was recorded against Klebsiella pneumonia with $21.0 \pm 0.58$, minimum activity against Salmonella typhi with $12.3 \pm 0.57$ and no activity was recorded against Pseudomonas aeruginosa. Streptomyces thermolilacinus VITDDK2 was antagonistic only towards Klebsiella pneumonia producing an inhibition zone of $15 \mathrm{~mm}^{15}$. Isolate no. 4 showed 
maximum activity against Staphylococcus aureus with $26.0 \pm 0.52$ and minimum against Salmonella typhi with 14.4 \pm 0.57 . Broad spectrum antibacterial Streptomyces species effective against both gram positive and gram negative bacteria was isolated from Khumbu region of $\mathrm{Nepal}^{7}$. Antibacterial activity of culture filtrate obtained from Streptomyces sp. No. 87 against gram positive and gram negative bacteria ${ }^{16}$. Streptomyces sampsonii GS 1322 was isolated from local garden soil and reported for their antifungal secondary metabolite production ${ }^{17}$.

A broad spectrum actinobacteria Streptomyces sindenensis strainLS1-128 having both antibacterial and antifungal activity was isolated from Loktak Lake in Eastern Indian ${ }^{18}$.

\section{Nucleotide sequence accession numbers:}

The nucleotide sequences of 16S rRNA isolated from the isolate no. 3 and isolate no. 4 investigated in this study have been identified as Streptomyces thermolilacinus and Streptomyces werreansis and deposited in the NCBI Gene Bank database library with accession number JN798175 and JN798174.

Table 2: The biochemical and physiological characteristics isolate no. 3 and isolate no. 4 :

\begin{tabular}{|lll|}
\multicolumn{1}{c}{ TESTS } & \multicolumn{2}{c|}{ RESULTS } \\
\hline \multicolumn{1}{c}{ Iso.3 } & Iso.4 \\
\hline Colony Pigmentation & + & + \\
Colony color & - & - \\
Aerial mycelium & Off white & white \\
Hemolysis on blood agar & Off white & white \\
Hydrolysis (\%w/v)of: & + & + \\
Starch & & \\
Casein & + & + \\
Urea & + & - \\
\hline Degradation (\%w/v)of: & - & - \\
Xanthine & & \\
Hypoxanthine & - & + \\
Tyrosine & + & - \\
Melanin production & - & - \\
Soluble pigment & + & - \\
\hline
\end{tabular}

\begin{tabular}{|c|c|c|}
\hline \multicolumn{3}{|l|}{ Enzymatic activity: } \\
\hline Catalase & + & + \\
\hline Oxidase & - & - \\
\hline H2S production & - & - \\
\hline Indole formation & - & - \\
\hline MR test & - & - \\
\hline VP test & - & - \\
\hline \multicolumn{3}{|l|}{ Temperature for growth } \\
\hline Optimum & $42^{\circ} \mathrm{C}$ & $30^{\circ} \mathrm{C}$ \\
\hline Optimum pH for growth & 7.5 & 7.5 \\
\hline \multicolumn{3}{|l|}{ Conc. of $\mathrm{NaCl}(\% \mathrm{w} / \mathrm{v})$} \\
\hline $1 \%$ & + & + \\
\hline $2 \%$ & + & + \\
\hline $3 \%$ & + & + \\
\hline $5 \%$ & - & + \\
\hline \multicolumn{3}{|l|}{ Carbon source utilization and } \\
\hline sugar fermentation $(1 \% \mathrm{w} / \mathrm{v})$ & + & + \\
\hline D-glucose & + & + \\
\hline Sucrose & - & -- \\
\hline D-xylose & - & - \\
\hline D-galactose & + & - \\
\hline Maltose & - & - \\
\hline L-arabinose & - & - \\
\hline Lactose & - & + \\
\hline Inositol & - & - \\
\hline Inuluin & - & - \\
\hline Raffinose & - & + \\
\hline Rhamnose & + & + \\
\hline Fructose & - & - \\
\hline Melibiose & - & - \\
\hline Sorbitol & - & - \\
\hline Mannitol & + & + \\
\hline Mannose & - & - \\
\hline \multicolumn{3}{|l|}{ Glycerol } \\
\hline \multicolumn{3}{|l|}{ Nitrogen Source $(1 \%$ w/v) } \\
\hline Peptone & + & + \\
\hline Yeast extract & + & + \\
\hline Casein & + & - \\
\hline Urea & - & - \\
\hline $\begin{array}{l}\text { Chemical characteristics } \\
\mathbf{G}+\mathbf{C} \text { content }(\mathbf{m o l} \%)\end{array}$ & $59.38 \%$ & $59.71 \%$ \\
\hline
\end{tabular}

(+) - Positive; (-) - Negative

Table 3: Antagonistic activities of Streptomyces species against clinical isolates of test pathogen:

\begin{tabular}{|c|l|c|c|c|}
\hline & \multicolumn{1}{|c|}{ Zone of Inhibition (mm) } \\
\hline S.NO & \multicolumn{1}{|c|}{ Clinical Isolates } & Isolate 3 & Isolate 4 & Positive Control \\
\hline 1. & S. aureus & $17 \pm 0.57$ & $26.0 \pm 0.52$ & $16.0 \pm 0.57$ \\
\hline 2. & B. subtilis & $14.0 \pm 0.57$ & $18.9 \pm 0.58$ & $18.0 \pm 0.57$ \\
\hline 3. & S.typhi & $12.3 \pm 0.57$ & $14.4 \pm 0.57$ & $15.6 \pm 0.57$ \\
\hline 4. & K.pneumoniae & $21.0 \pm 0.58$ & $20.0 \pm 0.52$ & $12.8 \pm 1.0$ \\
\hline 5. & P.aeruginosa & 0.0 & $16.0 \pm 0.57$ & $15.0 \pm 1.0$ \\
\hline
\end{tabular}

Data given are mean of three replicates \pm Standard error. S. aureus= Staphylococcus aureus, B. subtilis=Bacillus subtilis, S.typhi=Salmonella typhi, K.pneumoniae = Klebsiella pneumoniae, P.aeruginosa=, Psedomonas aeruginosa.

\section{CONCLUSION}

Streptomyces thermolilacinus and Streptomyces werreansis reported in this study showed significant antagonistic activities against some important gram negative and positive human pathogenic bacteria and reported first time from soil of Western Rajasthan. It is suggested that further studies on actinomycetes present in the Western Rajasthan's soil could provide novel species as well as novel antibiotics.

\section{ACKNOWLEDGEMENT}

The authors are grateful to Prof. Swarnjeet Kaur, Head, Department of Botany, Jai Narain Vyas University, Jodhpur for providing basic research facilities. 
1. Bredy, J.,. Bioactive Microbial Metabolites.J.Antibiot., 2005, 58:1-26.

2. Bull AT, Stach JEM., Marine actinobacteria: new opportunities for natural product search and discovery. Trends Microbiol , 2007.15: 491-499.

3. Difco laboratories, Bacto Actinomycetes Isolation Agar. code 0957: Difco supplementary literature. Difco laboratories, 1962.Detroit, Mich.

4. Madigan, M.T., Martinko J.M. and Parker J.Brock Biology Microorganisams. $8^{\text {th }}$ Edn., Prentice Hall International Inc., New Jersey, 1977.440-442.

5. Shirling, E. B. \& Gottlieb, D, Methods for characterization of Streptomyces species. Int. J. Syst. Bacteriol. 1966.16: 313-340.

6. Tresner, H.D., Hayes J.A. and Backus E.J.Differential tolerance of Streptomycetes to sodium chloride as a taxonomic aid. J. Appl. Microbiol., 1968. 16:1134-1136.

7. Pandey B, Ghimire P, Agrawal VP. Studies on the antimicrobial activity of actinomycetes isolated from Khumbu region of Nepal. PhD dissertation, 2004. Tribhuvan University, Kathmandu, Nepal.

8. Bergey's Manual of Determinative Bacteriology, J. G. Holt, N. R. Krieg, P. H. A. Sneath, J. T. Staley, S. T. Williams (eds.), 1994, ninth edn, Baltimore, Philadelphia, Hong Kong, London, Munich, Sydney, Tokyo: Williams \&Wilkins.

9. Bondartzev, A. S.,. Colour scale, Moskva, Leningrad: 1954, AN SSSR (in Russian).

10. Gordon, R.E. and Mihm J.M. The type species of the genus Nocardia. J.Gen. Microbiol., 1962. 27: 1-10.
11. Kuster, E. \& Williams, S. T., Media for the isolation of Streptomycetes: starch casein medium. Nature 1964.202:928-929.

12. Delahaye C, Rainford L, Nicholson A, Mitchell S, Lindo J, Ahmad M . Antibacterial and antifungal analysis of crude extracts from the leaves of Callistemon viminalis. Journal of Medical and Biological Sciences.3, 2009, 1-7.

13. Manjula C,Rajguru P.and Muthuselvan M., Screening for antibiotic sensitivity of free and immobilized actinomycetes isolated from India. Advances In Biological Research, 2009.3: 84-88.

14. Fleming H.P; Etchells JL, costilow R.L. Microbial inhibition by an isolate of Pediococcus from Cucumber brines, Applied Microbiology 1985.30:1040-1042.

15. Debananda S. Ningthoujam, Suchitra Sanasam, K. Tamreihao and Salam Nimaichand, Antagonistic activities of local actinomycete isolates against rice fungal pathogens. African Journal of Microbiology Research, 2009. 3(11) .737-742.

16. Charoensopharat K, Thummabenjapone P, Sirithorn P, Thammasirirak1 S. Antibacterial substance produced by Streptomyces sp. No. 87. African Journal of Biotechnology 2008. 7: 1362-1368.

17. Jain PK, Jain PC. Isolation, characterization and antifungal activity of Streptomyces sampsonii GS 1322. Indian J Exp Biol .2007. 45: 203-206.

18. Deepika L, Kannabiran K. Isolation and Characterization of Antagonistic Actinomycetes from Marine Soil. J Microbial Biochem Technol 2010. 2: 001-006. doi:10.4172/19485948.1000015. 